\title{
Assessment of genetic variability and heritability for quantitative traits between desi and kabuli chickpea genotypes
}

\author{
Quaid Hussain ${ }^{1,2}$, Nazir Ahmad², Rayyan Khan ${ }^{3}$, Muhammad Asim³, \\ Muhammad Adnan ${ }^{2}$, Tariq Aziz ${ }^{2}$ and Abrar Muhammad ${ }^{4}$ \\ 1. Oil Crops Research Institute of the Chinese Academy of Agricultural Sciences, Key Laboratory of Biology and \\ Genetic Improvement of Oil Crops, Ministry of Agriculture, Wuhan, Hubei Province, 430062-China \\ 2. Department of Plant Breeding and Genetics, Faculty of Crop Production Sciences, University of Agriculture, \\ Peshawar-Pakistan \\ 3. Department of Agronomy, Faculty of Crop Production Sciences, University of Agriculture, Peshawar-Pakistan \\ 4. Fujian Provincial Key Laboratory of Insect Ecology, Department of Plant Protection, Fujian Agriculture and \\ Forestry University, Fuzhou-China \\ *Corresponding author's email: quaid_hussain@yahoo.com
}

Citation

Quaid Hussain, Nazir Ahmad, Rayyan Khan, Muhammad Asim, Muhammad Adnan, Tariq Aziz and Abrar Muhammad. Assessment of genetic variability and heritability for quantitative traits between desi and kabuli chickpea genotypes. Pure and Applied Biology. Vol. 6, Issue 4, pp1111-1118. http://dx.doi.org/10.19045/bspab.2017.600119

Received: 24/04/2017 Revised: 23/08/2017

Accepted: 30/08/2017

Online First: 09/09/2017

\section{Abstract}

Twenty chickpea (Cicer arietinum L.) genotypes were evaluated for assessment of genetic variability and heritability for quantitative traits. This experiment was carried out in a randomized complete block (RCB) design with three replications. All chickpea genotypes revealed high significant differences for most of the traits. Analysis of variance showed highly significant differences for comparative performance of kabuli and desi genotypes. Mean value for seed yield $\left(\mathrm{kg} \mathrm{ha}^{-1}\right)$ of kabuli genotypes was $1210.1 \mathrm{~kg}$, which was comparatively less than mean value of desi genotypes which was $1823.9 \mathrm{~kg}$. Among kabuli genotypes, the analysis of variance showed significant differences for most of the traits. Mean square analysis in desi genotypes also revealed significant differences for most of the traits. Broad sense heritability estimates for yield and yield components was moderate to high. Results showed that genotypes NIFA-2005, NDC-4-20-5, SL-3-64, NDC-4-20-4 and NKC-5-S16 performed better and could be used in future breeding programs for the development of high yielding varieties in chickpea.

Keywords: Chickpea; Genetic variability; Heritability and quantitative traits

\section{Introduction}

Chickpea (Cicer arietinum L.), also known as bengal gram or garbanzo, is one of the earliest food legumes cultivated by man and plays a vital role in human diet and agricultural system. It belongs to family
Leguminosae and genus Cicer, approximately all Cicer species have $2 n=2 x=16$ chromosomes. Two distinct types of chickpea are recognized, i.e. desi and kabuli [1]. Genetic variability is a measure of the tendency of individual genotypes in a 
population to vary from one another. Variability is different from genetic diversity, which is the amount of variation seen in a population. The variability of a trait describes how much that trait tends to vary in response to environmental and genetic influences. Genetic variability also underlies the differential susceptibility of organisms to diseases and sensitivity to toxins or drugs. Causes of genetic are homologous recombination, immigration, translocation, polyploidy, genetic mutations. Genetic variation among the plant traits is important for breeding and in selecting desirable types. The average yield of chickpea in Pakistan is low as compared to another chickpea growing countries of the world. This is primarily due to poor genetic makeup of the cultivars, excessive vegetative growth, low tolerance to diseases and no availability of seeds of improved varieties. Genotypic correlation and path coefficient analysis provides the strength of the association between yield and its contributing traits [2].

Plant breeders are continuously endeavouring to improve the genetic potential of yield of this crop to meet the demands of the growing population. The approaches to make significant improvement in chickpea production require information on nature and magnitude of genetic variation in quantitative characters and their interrelationship in population comprising diverse genotypes, which are important fundamentals for systematic breeding programme [3].

Keeping in view the above-mentioned facts, the present investigations were planned with the following objectives to:

Examine the genetic variability for morpho yield characters in desi and kabuli chickpea genotypes.

Study the comparative performance of desi and kabuli chickpea.
Investigate heritability for different morphological and yield traits in chickpea.

\section{Materials and methods}

The experiment on assessment of genetic variability and heritability for quantitative traits between desi and kabuli chickpea genotypes was conducted at the experimental area, University of Agriculture, Peshawar during growing season 2013-14. The experimental material comprises of 10 desi and 10 kabuli chickpea genotypes, which were evaluated in the field environments in a randomized complete block design with three replications. The experimental plot involved four rows, each had 4 meter in length. Row to row and plantto-plant spaces was 30 and $10 \mathrm{~cm}$, respectively. The plot to plot distance was $60 \mathrm{~cm}$.

\section{Statistical analysis}

The information recorded on every parameter was subjected to analysis of variance (ANOVA) procedure suitable for a randomized complete block design through MSTATC PC program. The mean contrasts among chickpea genotypes for distinctive morphological and yield characteristics were measured by applying least significant differences (LSD) test at 5\% level of likelihood as proposed by Steel and Torrie [4].

Heritability broad sense $\left(\mathrm{h}_{2} \mathrm{~B} . \mathrm{S}\right)$ was calculated as suggested by Falconer [5] and Larik et al. [6] as follows: $\mathrm{h}_{2}=\mathrm{Vg} / \mathrm{Vp}$.

\section{Results and discussions} Days to 50\% flowering

Data analysis for days to $50 \%$ flowering showed significant $(\mathrm{p} \leq 0.05)$ differences among 20 chickpea genotypes (Table 1). It ranged from 121.33 to 128.67 days with an average value of 125.08 days. Early flowering was observed by genotype NKC5-S-14 (121.33 days) followed by NKC-5-S17 (122.00 days), while maximum days to $50 \%$ flowering were showed in genotype 
NKC-5-S-16 (128.67 days) followed by SL5-42 (128 days) (Table 2). [7] also reported similar results for days to $50 \%$ flowering in chickpea genotypes.

Analysis of variance for days to $50 \%$ flowering showed significant $(\mathrm{p} \leq 0.05)$ differences for comparison between kabuli and desi chickpea genotypes (Table 1). Average value for days to $50 \%$ flowering of kabuli genotypes was 124.33 , which was comparatively less than average value of desi genotypes which was 125.83 (Table 2). [8] also observed similar results i.e. highly significant variation days to $50 \%$ flowering in comparative performance between kabuli and desi chickpea genotypes. Among kabuli genotypes, this trait differed significantly, ranging from 121.33 to 128.67 days with a mean value of 124.33 days. The minimum days to $50 \%$ flowering for kabuli genotypes was showed by NKC-5-S-14 (121.33) and maximum days by genotype NKC-5-S-16 (128.67). In desi genotypes, non-significant differences were recorded for days to $50 \%$ flowering. It ranged from 123 to 128 days with an average value of 125.83 days. The minimum days to $50 \%$ flowering were recorded for genotype SL-3-64 (123) and maximum days were recorded by SL-5-42 (128) (Table 2).

Genotypic variance for days to $50 \%$ flowering was 1.68, while phenotypic variance was 7.48 with low heritability of 0.22 (Table 3). [9] also reported similar results of low heritability for days to $50 \%$ flowering in chickpea genotypes.

\section{Nodules per plant}

Analysis of variance revealed highly significant $(\mathrm{p} \leq 0.01)$ differences for number of nodules plant ${ }^{-1}$ among chickpea genotypes (Table 1). It ranged from 6.33 to 20.52 with a mean value 13.45 . Minimum number of nodules plant ${ }^{-1}$ was recorded for genotype SL-3-29 (6.33) followed by NKC10-99 (7.22), while genotype SL-3-64 was recorded maximum (20.52) number of nodules plant ${ }^{-1}$ followed by NKC-5-S13 (20.37) (Table 2). [10] also obtained similar results of highly significant variability for number of nodules plant ${ }^{-1}$ in chickpea genotypes.

Analysis of variance for number of nodules plant $^{-1}$ showed non-significant differences between kabuli and desi chickpea genotypes (Table 1). [10] also showed opposite results highly significant variation in comparative studied 47 chickpea genotypes. Among kabuli genotypes, showed highly significant $(\mathrm{p} \leq 0.01)$ differences for this trait, ranging from 7.22 to 20.73 with a mean of 13.29. The minimum number of nodules plant ${ }^{-1}$ was recorded for NKC-10-99 (7.22) and maximum number for genotype NKC-5-S13 (20.73). In desi genotypes, observed highly significant $(\mathrm{p} \leq 0.01)$ differences for this trait. It was ranging from 6.33 to 20.52 with an average value of 13.61. The minimum number of nodules plant ${ }^{-1}$ was recorded for genotype SL-3-29 (6.33) and maximum number were recorded for SL-3-64 (20.52) (Table 2).

Genotypic variance for number of nodules plant $^{-1}$ was 19.44 and phenotypic variance was 20.54. High heritability estimates for this trait 0.95 , respectively (Table 3 ). [10] also reported similar results of high heritability for number of nodules plant ${ }^{-1}$ in chickpea genotypes.

\section{Plant height}

Analysis of variance testified highly significant $(p \leq 0.01)$ differences among genotypes for plant height (Table 1). It ranged from 63.66 to $105.28 \mathrm{~cm}$ with an average value $83.54 \mathrm{~cm}$. The minimum plant height was observed for genotype SL-3-29 $(63.66 \mathrm{~cm})$ followed by NKC-10-99 (76.66 $\mathrm{cm})$, while genotype NKC-5-S15 recorded maximum $(105.28 \mathrm{~cm})$ plant height followed by NKC-5-S12 (102.85 cm) (Table 2). [9] also reported similar results of highly significant variation for plant height in chickpea genotypes. 
Table 1. Mean squares for days to $50 \%$ flowering (DF), Nodules plant ${ }^{-1}$ (NP), Plant height $(\mathrm{PH})$, Primary branches plant ${ }^{-1}(\mathrm{~PB})$, Pods plant $^{-1}(\mathrm{PD})$ and Seed yield $\left(\mathrm{kg} \mathrm{ha}^{-1}\right)(\mathrm{SY})$.

\begin{tabular}{|l|l|l|l|l|l|l|l|}
\hline S.O. V & df & DF & NP & PH & PB & PD & SY \\
\hline Replication & 2 & 1.22 & 2.78 & 47.83 & 0.53 & 54.46 & 220575 \\
\hline Genotypes & 19 & $10.84^{*}$ & $59.42^{* *}$ & $226.23^{* *}$ & $0.38^{*}$ & $135.43^{*}$ & $657383^{* *}$ \\
\hline Kabuli & 9 & $12.59^{*}$ & $71.84^{* *}$ & $282.39^{* *}$ & $0.36^{\mathrm{ns}}$ & $140.69^{* *}$ & $182176^{* *}$ \\
\hline Desi & 9 & $6.54^{\mathrm{ns}}$ & $53.44^{* *}$ & $129.95^{* *}$ & $0.25^{\mathrm{ns}}$ & $96.97^{*}$ & $577597^{* *}$ \\
\hline Kabuli v Desi & 1 & $33.75^{*}$ & $1.58^{\mathrm{ns}}$ & $587.37^{* *}$ & $1.76^{* *}$ & $434.16^{* *}$ & $5652320^{* *}$ \\
\hline Error & 38 & 5.79 & 1.10 & 9.28 & 0.18 & 29.71 & 55787 \\
\hline CV $(\%)$ & & 1.92 & 7.81 & 3.65 & 13.08 & 10.37 & 15.57 \\
\hline
\end{tabular}

Table 2. Mean values for days to $50 \%$ flowering (DF), Nodules plant ${ }^{-1}$ (NP), Plant height $(\mathrm{PH})$, Primary branches plant ${ }^{-1}(\mathrm{~PB})$, Pods plant $^{-1}(\mathrm{PD})$ and Seed yield $\left(\mathrm{kg} \mathrm{ha}^{-1}\right)(\mathrm{SY})$

\begin{tabular}{|l|l|l|l|l|l|l|l|}
\hline GROUP & GENOTYPES & $\mathbf{D F}$ & $\mathbf{N P}$ & $\mathbf{P H}$ & $\mathbf{P B}$ & $\mathbf{P D}$ & $\mathbf{S Y}$ \\
\hline KABULI & NKC-10-99 & 123.67 & 7.22 & 76.66 & 3.52 & 60.63 & 869.1 \\
\hline & NKC-5-S-12 & 124.33 & 16.71 & 102.85 & 3.14 & 60.10 & 1443.7 \\
\hline & NKC-5-S-14 & 121.33 & 11.40 & 81.85 & 3.09 & 57.97 & 861.6 \\
\hline & NKC-5-S-24 & 125.33 & 19.03 & 81.19 & 3.57 & 46.10 & 1209.8 \\
\hline & NKC-5-S-20 & 125.00 & 10.52 & 80.95 & 4.09 & 61.90 & 1434.7 \\
\hline & NKC-5-S-16 & 128.67 & 9.70 & 88.81 & 2.90 & 47.53 & 1589.3 \\
\hline & NKC-5-S-17 & 122.00 & 11.36 & 83.38 & 3.71 & 46.50 & 1351.7 \\
\hline & NKC-5-S-21 & 123.00 & 8.00 & 80.85 & 3.52 & 52.20 & 1141.9 \\
\hline & NKC-5-S-13 & 125.00 & 20.37 & 84.85 & 3.38 & 54.83 & 1026.0 \\
\hline & NKC-5-S-15 & 125.00 & 18.59 & 105.28 & 3.18 & 64.33 & 1172.8 \\
\hline & MEAN & 124.33 & 13.29 & 86.67 & 3.41 & 55.24 & 1210.1 \\
\hline & NDC-4-20-4 & 125.67 & 19.283 & 79.99 & 2.85 & 44.40 & 2056.7 \\
\hline & NDC-4-20-2 & 127.00 & 12.36 & 88.76 & 3.19 & 51.33 & 1551.7 \\
\hline & NDC-4-20-3 & 124.67 & 11.33 & 79.05 & 3.33 & 46.33 & 1798.0 \\
\hline & NDC-4-20-5 & 125.67 & 13.37 & 84.95 & 2.71 & 48.20 & 2297.3 \\
\hline & SL-3-64 & 123.00 & 20.52 & 79.42 & 2.71 & 43.23 & 2065.9 \\
\hline & SL-5-42 & 128.00 & 14.17 & 83.95 & 3.57 & 53.43 & 1430.9 \\
\hline & SL-3-15 & 124.67 & 10.29 & 81.90 & 2.80 & 45.93 & 1609.8 \\
\hline & SL-3-29 & 125.67 & 6.33 & 63.66 & 3.14 & 48.27 & 1002.9 \\
\hline & SL-8-14 & 127.00 & 16.30 & 81.18 & 3.28 & 61.10 & 1944.8 \\
\hline & NIFA-2005 & 127.00 & 12.18 & 81.23 & 3.09 & 56.40 & 2481.3 \\
\hline & Mean & 125.83 & 13.61 & 80.41 & 3.07 & 49.86 & 1823.9 \\
\hline & Total Mean & 125.08 & 13.45 & 83.54 & 3.24 & 52.55 & 1517 \\
\hline & LSD (5\%) & 3.98 & 1.74 & 5.03 & 0.7 & 9.01 & 390.41 \\
\hline
\end{tabular}


Table 3. Genetic, environmental and phenotypic variances with heritability (bs) for various traits of chickpea genotypes.

\begin{tabular}{|c|c|c|c|c|}
\hline Traits & $\mathbf{V g}$ & Ve & Vp & $\mathbf{h}^{2}$ \\
\hline Days to $50 \%$ flowering & 1.68 & 5.80 & 7.48 & 0.22 \\
\hline Number of nodules plant ${ }^{-1}$ & 19.44 & 1.10 & 20.54 & 0.95 \\
\hline Plant height $(\mathrm{cm})$ & 72.32 & 9.28 & 81.59 & 0.89 \\
\hline Primary branches plant ${ }^{-1}$ & 0.07 & 0.18 & 0.25 & 0.27 \\
\hline Number of pods plant ${ }^{-1}$ & 35.24 & 29.71 & 64.95 & 0.54 \\
\hline Seed yield $\left(\mathrm{kg} \mathrm{ha}^{-1}\right)$ & 200532.00 & 55787.00 & 256319.00 & 0.78 \\
\hline
\end{tabular}

Analysis of variance for plant height revealed highly significant $(\mathrm{p} \leq 0.01)$ differences for comparative performance between kabuli and desi chickpea genotypes (Table 1). Mean value for plant height of kabuli genotypes was $86.67 \mathrm{~cm}$, which was comparatively greater than mean value of desi genotypes which was $80.41 \mathrm{~cm}$ (Table 2). [8] also observed similar results in comparative performance between kabuli and desi chickpea genotypes. Among kabuli genotypes, analysis of variance showed highly significant $(\mathrm{p} \leq 0.01)$ differences for this trait. Plant height ranged from 76.66 to $105.28 \mathrm{~cm}$, with an average value $86.67 \mathrm{~cm}$. The minimum plant height recorded for NKC-10-99 (76.66 cm) and maximum height for genotype NKC-5-S15 (105.28 $\mathrm{cm})$. In desi genotypes, highly significant $(p \leq 0.01)$ differences were observed for plant height. It ranged from 63.66 to $88.76 \mathrm{~cm}$ with an average value of $80.41 \mathrm{~cm}$. The minimum plant height was recorded for genotype SL-3-29 (63.66 cm) and maximum height was recorded for NDC-4-20-2 (88.76 $\mathrm{cm})$ (Table 2).

Genetic and phenotypic variances for the plant height were 72.32 and 81.59. The high heritability for plant height was 0.89 respectively (Table 3). [11, 12] also reported similar results of high heritability for plant height in chickpea genotypes.

\section{Primary branches per plant}

Analysis of variance exhibited significant $(\mathrm{p} \leq 0.05)$ differences among chickpea genotypes for number of primary branches plant $^{-1}$ (Table 1). It ranged from 2.71 to 4.09 , with the mean value 3.24. The minimum number of primary branches was observed for genotypes NDC-4-20-5 and SL-3-64 (2.71) followed by SL-3-15 (2.81), while genotype NKC-5-S20 showed maximum (4.09) number of primary branches plant $^{-1}$ followed by NKC-5-S17 (3.71). [13] also obtained similar results of significant variability for number of primary branches plant ${ }^{-1}$ in chickpea genotypes.

Analysis of variance for number of primary branches plant ${ }^{-1}$ presented highly significant $(\mathrm{p} \leq 0.01)$ differences between kabuli and desi genotypes (Table 1). Among kabuli genotypes, analysis of variance showed nonsignificant differences for the said trait, ranging from 2.90 to 4.09 with an average value 3.41. The maximum number of primary branches plant $^{-1}$ was recorded for NKC-5-S20 (4.09) and minimum number for NKC-5-S16 (2.90). In desi genotypes, the analysis of variance exhibited nonsignificant differences for this trait. It ranged from 2.71 to 3.57 with the mean value of 3.07. The minimum number of primary branches plant ${ }^{-1}$ was recorded for genotypes NDC-4-20-5 and SL-3-64 (2.71) and maximum value was recorded for genotype SL-5-42 (3.57) (Table 2).

Genetic variance for number primary branches plant $^{-1}$ was 0.07 and phenotypic variance was 0.25 , with low heritability of 0.27 (Table 3). [14] also obtained similar results of low heritability for number of 
primary branches plant ${ }^{-1}$ in chickpea genotypes.

\section{Pods per plant}

Analysis of variance showed highly significant $(p \leq 0.01)$ differences for pods plant $^{-1}$ among chickpea genotypes (Table 1). It ranged from 43.23 to 64.33 ; with an average value 52.55. Minimum pods plant ${ }^{-1}$ was observed by genotype SL-3-64 (43.23) followed by NDC-4-20-4 (44.40), while maximum pods were recorded by genotype NKC-5-S15 (64.33) which was followed by NKC-5-S20 (61.90), SL-8-14 (61.10) and NKC-10-99 (60.63) (Table 2). Similar results were recorded by Ramanappa et al. [13] reported significant variation for pods plant $^{-1}$ in chickpea genotypes.

Analysis of variance for pods plant $^{-1}$ divulged highly significant $(\mathrm{p} \leq 0.01)$ differences between kabuli and desi genotypes (Table 1). Mean value for pods plant $^{-1}$ of kabuli genotypes was 55.24, which was comparatively greater than mean value of desi genotypes which was 49.86. [8] also observed similar results in comparative performance between kabuli and desi chickpea genotypes. Among kabuli genotypes, analysis of variance showed highly significant $(p \leq 0.01)$ differences for the said trait. It ranged from 46.10 to 64.33 with an average value 55.24. Maximum pods plant ${ }^{-1}$ had taken by genotype NKC-5S15 (64.33) and minimum by genotype NKC-5-S24 (46.10). In desi genotypes, significant differences were observed for pods plant $^{-1}$. Pods per plant ranged from 43.23 to 61.10 , with an average value 49.86 . Minimum pods plant ${ }^{-1}$ was recorded by SL3-64 (43.23) and maximum for SL-8-14 (61.10) (Table 2).

Genotypic and phenotypic variance for pods plant $^{-1}$ was 35.24 and 64.95 , with a moderate heritability of 0.54 , respectively (Table 3 ). [15] also reported similar results of moderate heritability for pods plant $^{-1}$ in chickpea genotypes.

\section{Seed yield $\left(\mathrm{kg} \mathrm{ha}^{-1}\right)$}

Mean square data regarding seed yield manifested highly significant $(\mathrm{p} \leq 0.01)$ differences among chickpea genotypes (Table 1). It ranged from 861.6 to $2481.3 \mathrm{~kg}$ $\mathrm{ha}^{-1}$, with an average value $1517.0 \mathrm{~kg} \mathrm{ha}^{-1}$. Genotype NKC-5-S14 was recorded minimum (861.6 $\left.\mathrm{kg} \mathrm{ha}^{-1}\right)$ seed yield, which was followed by NKC-10-99 (869.1 kg ha$\left.{ }^{1}\right)$. However, maximum seed yield (2481.3 $\mathrm{kg} \mathrm{ha}^{-1}$ ) was recorded by genotype NIFA2005 which was followed by NDC-4-20-5 (2297.3 kg ha $\left.{ }^{-1}\right)$, SL-3-64 (2065.9 kg ha-1) and NDC-4-20-4 (2056.7 kg ha-1) (Table 2). [16] also showed similar results for seed yield in chickpea genotypes.

Analysis of variance for seed yield showed highly significant $(\mathrm{p} \leq 0.01)$ differences for comparative performance between kabuli and desi chickpea genotypes (Table 1). Mean value for seed yield of kabuli genotypes was $1210.1 \mathrm{~kg}$, which was comparatively less than mean value of desi genotypes which was $1823.9 \mathrm{~kg}$ (Table 2). [8] also observed similar results in comparative performance between kabuli and desi chickpea genotypes. Among desi genotypes, analysis of variance showed highly significant $(\mathrm{p} \leq 0.01)$ differences for this said trait, ranging from 1002.9 to 2481.3 $\mathrm{kg} \mathrm{ha}^{-1}$ with an average value of $1823.9 \mathrm{~kg}$ $\mathrm{ha}^{-1}$. The minimum seed yield was recorded for SL-3-29 (1002.9 $\left.\mathrm{kg} \mathrm{ha}^{-1}\right)$ and maximum yield for genotype NIFA-2005 $(2481.3 \mathrm{~kg}$ $\mathrm{ha}^{-1}$ ). Among kabuli genotypes, highly significant $\quad(\mathrm{p} \leq 0.01) \quad$ differences were observed for seed yield $\left(\mathrm{kg} \mathrm{ha}^{-1}\right)$. It ranged from 861.6 to $1589.3 \mathrm{~kg} \mathrm{ha}^{-1}$ with an average value was $1210.1 \mathrm{~kg} \mathrm{ha}{ }^{-1}$. Genotypes NKC-5-S14 was recorded minimum (861.6 $\mathrm{kg} \mathrm{ha}^{-1}$ ) seed yield and maximum yield was recorded for NKC-5S16 (1589.3 kg ha-1) (Table 2).

Genotypic and phenotypic variances for seed yield were 200532.00 and 256319.00 with high heritability of 0.78 , respectively 
(Table 3). [17] also reported similar results of high heritability for this trait in chickpea genotypes.

\section{Conclusions}

Sufficient variability was observed for different traits among 20 genotypes of chickpea. High heritability estimates were observed for most of the traits, which has the extent for advance improvement. Comparative performance between kabuli and desi chickpea genotypes showed sufficient variability and NIFA-2005 (Desi) showed high yield $\mathrm{kg} \mathrm{ha}^{-1}$. Among kabuli genotypes, NKC-5-S16 showed high yield, while among desi genotypes, NIFA-2005 exhibited high yield and could be used in future breeding programs for the development of high yielding cultivars.

\section{Authors' contribution}

Conceived and designed the experiments: Q Hussain, Performed the experiments: Q Hussain \& T Aziz, Analyzed the data: N Ahmed, M Asim \& A Muhammad, contributed reagents/ materials/ analysis tools: Q Hussain, M Adnan \& R Khan, Wrote the paper: Q Hussain.

\section{References}

1. Gaur PM, Tripathi, Gowda S, Rao CLLR, Sharma GV, Pande HC \& Sharma SM (2010). Chickpea Seed Production Manual. Patancheru, Andhra Pradesh, India: ICRISAT.

2. Naveed MT, Ali Q, Ahsan M \& Hussain B (2012). Correlation and path coefficient analysis for various quantitative traits in chickpea (Cicer arietinum L.). Inter $J$ Agro Veter Med Sci (IJAVMS) 6(2): 97106.

3. Arshad M, Bakhsh A, Zubair M \& Ghafoor A (2003). Genetic variability and correlation studies in chickpea (Cicer arietinum L.). Pak J Bot 35(4): 605-611.

4. Steel RGD \& Torrie JH (1980). Principles and procedures of statistics, a biological approach, 2nd ed. Mc Graw Hill, Inc. New York, Toronto, London.
5. Falconer DS (1970). Introduction to quantitative genetics. Longman \& Groups Ltd., London, UK.

6. Larik AS, Hafiz HMI \& Khushk AM (1989). Estimation of genetic parameters in wheat populations derived from intercultivaral hybridization. Pakphyton 1: 51-56.

7. Gul R, Khan H, Bibi M, Ain QU \& Imran B (2013). Genetic analysis and interrelationship of yield attributing traits in chickpea (Cicer arietinum L). J Anim Plant Sci 23(2): 512-526.

8. Tripathi S, Sridhar V, Jukanti AK, Suresh K, Rao BV, Gowda CL \& Gaur PM (2012). Genetic variability and interrelationships of phenological, physicochemical and cooking quality traits in chickpea. Plant Genetic Res 10(3): 194-201.

9. Zeeshan M, Arshad W, Ali S, Owais M, Zulkiffal M \& Hussain M (2013). Genetic divergence and character association in chickpea (Cicer arietium) under rainfed conditions. Wudpecker J Agric Res 2(1): 28-32.

10. Gul, R, Khan H, Khan NU \& Khan FU (2014). Characterization of chickpea germplasm for nodulation and effect of rhizobium inoculation on nodules number and seed yield. The J Anim Plant Sci 24(5): 1421-1429.

11. Ali Q, Ahsan M, Khaliq I, Elahi M, Shahbaz M, Ahmad W \& Naees M. 2011. Estimation of genetic association of yield and quality traits in chickpea (Cicer arietinum L.). Int Res J Plant Sci 2(6): 166-169.

12. Ali Q, Tahir MHN, Sadaqat HA, Arshad S, Farooq J, Ahsan M, Waseem M \& Iqbal M (2011). Genetic variability and correlation analysis for quantitative traits in chickpea genotypes (Cicer arietinum L.). J Bacteriology Res 3(1): 6-9.

13. Ramanappa TM, Chandrashekara K \& Nuthan D (2013). Analysis of variability 
for economically important traits in chickpea (Cicer arietinum L.). Int J Res Applied Nat Soci Sci (IJRANSS) 1(3): 133-140.

14. Malik SR, Bakhsh A, Asif MA, Iqbal U \& Iqbal SM (2010). Assessment of genetic variability and interrelationship among some agronomic traits in chickpea. Int J Agric Bio 12(1): 81-85.

15. Padmavathi PV, Murthy SS, Rao VS \& Ahamed ML (2013). Correlation and path coefficient analysis in Kabu Farshadfar E, Mahtabi E, Safavi SM \& Shabani A (2013). Estimation of variability and genetic parameters in chickpea (Cicer arietinum L.) genotypes. Int J Agro Plant Prod 4(10): 2612- 2616. 21.

16. Farshadfar E, Mahtabi E, Safavi SM \& Shabani A (2013). Estimation of variability and genetic parameters in chickpea (Cicer arietinum L.) genotypes. Int J Agro Plant Prod 4(10): 2612- 2616.

17. Akhtar LH, Pervez MA \& Nasim M (2011). Genetic divergence and interrelationship studies in chickpea (Cicer arietinum L.). Pak J Agri Sci 48(1): 35- 39.li chickpea (Cicer arietinum L.). Int J Applied Bio Pharm Tech. 4(3): 107-110. 